Aims To demonstrate that children's nurses working at a specialist advanced and consultant level can make a significant impact and contribution to the redesign, development and delivery of effective services for children, young people (CYP) and their families.

To develop a shared understanding of a flexible transparent career framework with commissioners, managers and nurses which enables advanced clinical practice and leads improved health outcomes for CYP.

Methods A group of expert children's nurses from a range of disciplines and specialisms collaborated to review national and professional policy guidance to gain consensus regarding the incremental development of specialist and advanced careers which are sustainable, add value and contribute to new interdisciplinary ways of working.

Real life nursing roles and services exemplars were used to illustrate innovative developments. These ranged from child specific acute care alternatives to A\&E through to nurse led rapid access clinics for the assessment and diagnosis of long term conditions such as diabetes and also to clinical academic research roles which enable reciprocal practice and research synergy.

Results The guidance document created recognises that health outcomes for CYP in the United Kingdom are in many ways subordinate to those in comparable European countries. This led to recognition of the need for a fundamental review of child health services, and modernisation of the workforce for future service provision.

The importance of a flexible career framework which supports clinical and academic expertise developing in parallel has been highlighted as integral. The key attributes of specialist, advanced and consultant level practice are made transparent to support a planned approach to commissioning and developing services.

Innovative exemplars highlighted potential for improved patient experience, reduced admission rates and length of stay. Advanced practitioners challenge existing practice and work autonomously, educate others and build a research and evidence led care environment.

Conclusion This important guidance document demonstrates that children's nurses working at advanced levels of practice across a range of healthcare settings can lead the way to achieving excellence in health care and health outcomes.

\section{G219 LOOKED AFTER CHILDREN'S EXPERIENCES OF NURSING IN A SOCIAL CARE CONTEXT}

L Graham-Ray. Safeguarding and Quality, Central London Community Health Care Trust, London, UK

\subsection{6/archdischild-2015-308599.213}

Looked after Children is a term introduced by the Children Act (1989) which refers to all Children in public Care, including those who may live at home with their parents but who are the subject of Care orders. There were 67,050 Looked after Children in England and Wales at 31 March 2012 (DfF 2012). This figure has been rising over the last few years. As Looked after Children's nurse I have become very interested as to why, and what it is about being a nurse, that makes a difference to Looked after Children and Care Leavers. I would like to understand some of the reasons why they are happy to see us and let us help them with their health issues. This study examines research what it is about nurses working in social Care that makes a difference to Looked after Children and Care Leavers health, but perhaps more importantly what do Looked after Children and Care Leavers think about this and what do they say about it when asked?

\section{G220 ABSTRACT WITHDRAWN}

\section{G221 EARLY HELP IN EARLY YEARS: PROFESSIONAL REVIEW OF A UNIVERSAL ASSESSMENT TOOL}

T Redwood, S Neill, S Church, M Spencer. Institute of Health and Wellbeing, University of Northampton, Northampton, UK

\subsection{6/archdischild-2015-308599.214}

Serious case reviews nationally have highlighted the need for child care services to improve communication between professionals, to focus more on the voice of the child than of the adults involved and to develop a consistent approach to assessment of risk. A universal assessment tool for use by all professionals involved with families (from pregnancy to 2.5 years of age) named "My Family Profile" was developed by a multiagency team to address these issues. Independent formal professional review of the early draft formed a key element in the development of this intervention.

Aim To discuss the importance of formal professional review during intervention design using the example of the development of a multiagency family assessment tool.

Method Focus group methodology was employed for the professional review stage in the development of our multiagency tool, as it provides a valuable opportunity to discuss, evaluate and question within a constructive environment. This professional review focus group aimed to ascertain the views of child care professionals on the structure, format and usability of "My Family Profile" prior to pilot testing in practice. It was conducted in April, 2014 with professionals representing both pilot sites: three midwives, three health visitors and two early year's practitioners. The focus group was audiorecorded and transcribed, then subjected to thematic analysis.

Results In total the four themes presented below (Table 1) were identified from the analysis:

Abstract G221 Table 1 Themes from the professional review
1. Information gathering and sharing
2. Child centred
3. Research in practice
4. Workload concerns and digital format

Findings were used to revise the structure and content of the tool prior to pilot testing. Each of the first three themes generated alterations or additions in "My Family Profile". However the fourth theme was an emerging concern of potential impact and as such is a recommendation prior to implementation.

Conclusion The findings indicate support from practitioners for the implementation of "My Family Profile". These findings demonstrate the value of using a multiagency professional review within intervention design and should be highlighted as best practice. It is important to acknowledge professional ownership is not only a part of the design process but potentially an aspect of professional engagement with "My Family Profile" in practice. 